\title{
Pedro Herreros (1890-1937) Un poeta español atrapado por la modernidad de Buenos Aires
}

\author{
Pedro Herreros (1890-1937)
}

A Spanish poet trapped by the modernity of Buenos Aires

\begin{abstract}
Alfonso Rubio Hernández
Profesor Titular del Departamento de Historia/Facultad de Humanidades. Universidad del Valle (Cali, Colombia)

Doctor en Sistemas de Información y Documentación por la Universidad de Zaragoza (España) alfonso.rubio@correounivalle.edu.co
\end{abstract}

\begin{abstract}
Resumen: Las abundantes marcas autobiográficas que recorren la obra poética de Pedro Herreros muestran la mirada de un emigrante desengañado que en difíciles condiciones económicas tuvo que adaptarse a vivir en la modernidad capitalista del Buenos Aires de principios del siglo XX. Para entender sus experiencias vivenciales es necesario ponerlas en relación con el contexto histórico-social de emigración en el que vivió, tanto en el país de donde parte (España) como en el país que lo recibe (Argentina).
\end{abstract}

Palabras clave: emigración, España, Buenos Aires, Pedro Herreros, siglo XX.
Abstract: Pedro Herrero's work, plenty of autobiographical marks, shows the point of view of a deceived immigrant that had to adjust to the modern and capitalist Buenos Aires of the early twentieth century with great economic difficulty. To understand his experiences, it is necessary to consider the socio-historical background he lived in, taking into account the country where he started (Spain) and the country that foster him (Argentina).

Key words: emigration, Spain, Buenos Aires, Pedro Herreros, twentieth century. 


\section{Introducción}

Las políticas argentinas, desde mediados del siglo XIX, fomentaron, mediante corrientes ideológicas positivistas de desarrollo y progreso civilizado, la recepción de inmigrantes que podían colonizar territorios y mejorar la industria. A partir de 1880, a medida que se iban consolidando las instituciones políticas, Argentina entró en un periodo de inmigración masiva que se prolongó hasta 1914.

Es en este contexto social cuando el poeta Pedro Herreros llega a Buenos Aires, en el año de 1908. Nace en 1890 en la población de Arnedo de la que se llamaba por aquel entonces Provincia de Logroño, actual Comunidad Autónoma de La Rioja (España), y habitaba en un medio rural en condiciones de vida que hacían difícil la promoción social y económica. A este motivo de su emigración, el de querer mejorar económicamente, que el propio poeta señala en su obra, se añadió otro de no menor trascendencia: el temor a ser llamado a quintas cuando en España se estaban dando los conflictos militares en sus posesiones de ultramar. Por ello, la deserción en el país durante aquellos años fue numerosa.

Estas circunstancias son las que hacen emigrar a Herreros cuando contaba con 18 años de edad a la capital argentina. Toda su carrera literaria se desarrolló allí desde que en 1915 publicara su primer título (El Libro de los Desenfados) y en 1924 fuera coronado Poeta de la Boca por el conocido escritor bonaerense Conrado Nalé Roxlo (HERREROS, 1915).

En 1928 contrajo matrimonio con Ernestina Rosa Cerda Delgado, tuvo dos hijos (Eduardo Pedro, en 1929 y Nelly Herreros, en 1931) y desde 1935, por problemas de salud, se radicó en las cercanías de la ciudad de Córdoba, capital de la provincia homónima, donde fundó La Gaceta Serrana, primer periódico salido en la Villa de Unquillo, y la revista La Risa, dedicada a costumbres y anécdotas de la vida cordobesa.

Al poco tiempo de trasladarse a la ciudad de Villa Allende, algo más cercana a la capital cordobesa que Unquillo, murió en un 14 de octubre de 1937. Su vida fue corta (47 años), pero su obra poética contó al menos con un estimable de ocho títulos y fue adscrito a un movimiento literario de importantes repercusiones literarias que se denominó Sencillismo, donde destacó el conocido poeta argentino Baldomero Fernández Moreno, íntimo amigo del poeta español. Su actividad cotidiana, envuelta 
durante mucho tiempo en penurias económicas, siempre giró alrededor de unas amistades que crearon círculos artísticos, de sus proyectos literarios y de sus colaboraciones en distintas revistas y diarios argentinos.

El escritor y periodista del diario Crítica, Enrique González Tuñón, habló de Pedro Herreros como de uno de los corazones nobles por donde fluyen emociones en medio de la indiferencia citadina, de un poeta que "gastó las suelas de sus zapatos en un camino lunático por las calles de la urbe", de un hombre bondadoso y triste:

Bondadoso [dice González Tuñón] porque ama a los niños que quedan en las plazas (manos cordiales de Buenos Aires) y que le recuerdan su infancia triste con esa profunda tristeza de los alejados del hogar, con esa honda melancolía de los inmigrantes que arriban a puertos distintos con una angustia antigua y un recuerdo anclado en el corazón (DIARIO CRÍTICA, 1927: 3).

Antes de contraer matrimonio, Herreros anduvo por todas las calles de Buenos Aires durante 20 años, fue un perfecto conocedor de los espacios de sociabilidad artística e intelectual que se crearon en el palpitante Buenos Aires de principios de siglo $\mathrm{XX}$, y de las numerosas figuras que los poblaron, muchas veces por ser amigo de ellas. Los rasgos autobiográficas que recorren la obra de Pedro Herreros, centralmente los poemarios Buenos Aires grotesco y otros motivos (1922), Poemas egotistas (1923) y Las trompas de Falopio (1924), muestran tres espacios que, solo o en compañía, el poeta habitó como si fuera parte de ellos mismos: la calle, el café y el prostíbulo.

Por ello la mirada de Herreros no será la mirada crítica que juzga a distancia; sus experiencias vivenciales definen a un emigrante que en difíciles condiciones económicas y sin familia, tuvo que adaptarse a vivir en la calle, y por su condición autoafirmada de poeta frecuentó los círculos literarios y ambientes libreros del Buenos Aires de la época. La hoja de vida de un poeta español en Buenos Aires. Pedro Herreros, 1890-1937, es una obra dedicada a la vida y poesía del poeta español que trata con detalle estos aspectos de su sociabilidad artística (RUBIO, 2018). Sin embargo, de ella, adaptamos para esta ocasión únicamente los asuntos más relacionados con el contexto social de emigración española de comienzos del siglo XX, y el contexto bonaerense de recepción de emigrantes, que pone de manifiesto una situación social inestable, la que Pedro Herreros padeció y reflejó en su poesía. 


\title{
1. Emigrante en Buenos Aires. De un pueblo de la provincia de Logroño
}

\author{
Vería ciudades y tierras y mar... \\ ¿Qué sabía yo \\ lo que era la vida sin amor ni hogar! \\ Pero ninguno lloró \\ Pedro Herreros
}

Desde Buenos Aires, los versos de Pedro Herreros no dejarán de recordar su pueblo natal. Su primer poemario publicado, El libro de los desenfados (1915), habla de las lavanderas del río Cidacos, el río que cruzaba la población de Arnedo, y de los "famosos hornos de cocer pan", con los que allí había nacido y crecido (HERREROS, 1915: 45 [XIII] y 46 [XIV]).

Ocho años más tarde, en 1923, cuando Herreros contaba con veintitrés años de edad y llevaba viviendo quince en la capital argentina, sus Poemas egotistas muestran un "alma entristecida" y pide a Dios, un referente constante en toda su obra, le libre de la "amarga tragedia de mi vida". Es consciente de haber dejado atrás definitivamente "los días rosados de mi risueña infancia/ con mi madre, mi padre...y mi ignorancia"; de ser un emigrante ("me lancé a conquistar el Nuevo Mundo") que despierta al mundo donde está, y de saber que desde entonces su alma, "con conciencia y con luz,/ lleva una negra cruz". El contraste entre la vida familiar y pueblerina que llevaba en España y la vida de unos habitantes que se desenvolvían en una capital que estaba creciendo monstruosamente desde finales del siglo XIX, devora su estabilidad emocional: "Cada día es más amarga mi pena/ nacida en mi alma al choque/ de mi vida con la vuestra" (HERREROS, 1923: 12, “La tragedia de ver”; 25, "Desesperanza”).

La vida en Buenos Aires no le es fácil ("mi larga y trágica pobreza”) y la soledad ("Trece años que estoy solo", dice en el poema titulado "Año nuevo" que posiblemente escribe en 1921), le hace sentir un "terror profundo": “¡Sólo la muerte tiene/ lo que a mí me hace falta//...La mirada vaga/ voy con tentaciones de tirarme al agua". La desolación es extrema y el poeta, "con el alma muerta y la carne cansada", "con el alma y la carne entristecida", continuamente confiesa a Dios su estado de desesperación motivada, en gran medida, por el peso de la soledad y el deseo, no satisfecho todavía, de formar una familia (HERREROS, 1923: 9, "Me confieso a Dios"; 
10, "Lamentación"; 14, "Esplín”; 22, "Dormir es lo mejor"; 32, “Año nuevo"; 41, “Cómo no me voy a cansar"):

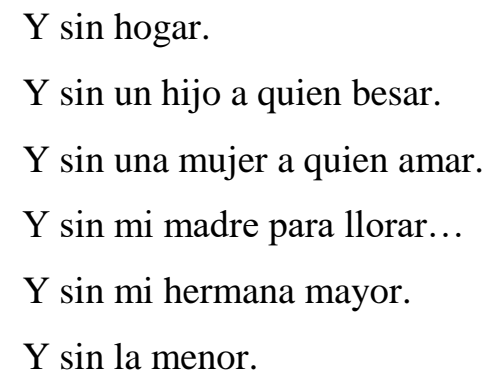

Sus padres y sus hermanos, sobre todo sus hermanas, aparecen a lo largo de Poemas egotistas (1923), su tercera obra publicada: "Mi padre: Nicolás Herreros y Garrido, /fue bueno: amaba el árbol, el pájaro y el nido" ("Mi padre”); "Mis hermanos más viejos/ me dieron al marchar/ muchos consejos." ("Pero ninguno 1loró"); "Es cierto que tengo hermanas./ Pero están muy lejos de mí" ("Lamentación”). Especial parece ser la relación que mantuvo con su hermana menor, Felisa, a quien dedica el poema que hace explícito su nombre, "A mi hermana Felisa": "Recibe, hermana, en esta rosa de pensamiento,/ lo mejor de mi alma por tus cartas cordiales./ Todo, en ellas, son dulces bálsamos fraternales/ para mi corazón y para mi tormento". En la situación de orfandad, miseria y soledad en la que se encuentra, las cartas de su hermana serán motivo de alegría y recuperación anímica: "Hoy recibí tu carta, hermana mía./ Y ha sido para mí como una epifanía.// Por eso el corazón me canta esta mañana:/ “Alégrate, poeta, que aún tienes una hermana." (“Miserere”) (HERREROS, 1923: 6, 8, 10, 11 y 15). ${ }^{1}$

En el mismo libro, son numerosas las referencias a parajes campestres de su pueblo natal en el poema que titula Paisaje castellano, cuando recuerda su infancia (HERREROS, 1923: 75-76). En poemarios posteriores como Poesía pura (1926) y Cantos de amor (1930), Pedro Herreros volverá a hablar de su infancia. El poema "Nocturno castellano" del primero de ellos se detiene en "aquella noche...bien recordada", cuando el río Cidacos, el "río que me encantaba", "a la luna,/ era blanco, era de plata", y "como yo era muy pequeño,/ "mi hermana...de la mano me llevaba"

\footnotetext{
${ }^{1}$ En el ejemplar de El libro de los desenfados que conserva la Biblioteca del Instituto de Estudios Riojanos en La Rioja (España), Pedro Herreros incluye una dedicatoria a su hermana pequeña: "A mi querida hermana Felisa. Pedro. Buenos Aires, junio de MCMXV".
} 
(HERREROS, 1926: 61-62). ${ }^{2}$ Mundo de recuerdos y remembranzas este del exilio, dice Gonzalo Santonja del también poeta Manuel Altolaguirre en su estancia cubana, "cuando el vivificador fluir de éstos se erige en apasionada razón de ser, en prueba palpable de personal existencia y definitivo testimonio de identidad" (SANTONJA, 1995: 41).

Cantos de amor (1930) está dedicado a quien fuera su mujer, Ernestina Rosa Cerda. Su poema homónimo relata el momento en que surge el amor con ella:

$$
\begin{aligned}
& \text { Por fin esta primavera } \\
& \text { hizo el milagro el Amor. } \\
& \text { ¿Sabéis? Llegó la Esperada, } \\
& \text { y una mirada bastó } \\
& \text { para encender la divina } \\
& \text { hoguera en mi corazón. }
\end{aligned}
$$

Realmente el poema es la confesión de un "dulcísimo secreto" dirigido (“¿Sabéis?”) a sus hermanas: “Hermanitas, soy feliz./ Y, gracias, desde aquí, doy a los dulces ojos negros/ que me han traído el amor". Son ya veintidós años los que Herreros lleva viviendo en Buenos Aires e incluso, cuando conoce a Ernestina, no puede dejar de evocar emotivos lazos que le atan a sus raíces natales, pues le manifiesta el deseo de que sea "mi novia y mi hermana". Agradeciéndole su compañía, le dice que "tú me has querido/ -como soñaba yo, como había pedido-/ con un amor de novia que sabe ser hermana" (HERREROS, 1930: 17-18 "Cantos de Amor", 44 "Deseo" y 49 “Agradecimiento") (HERREROS, 1930: 17-18, "Cantos de Amor"; 44, "Deseo"; 49, "Agradecimiento").

Escenarios, ambientes, costumbres y personajes familiares de un lugar con el que convivió durante dieciocho años antes de partir para la Argentina, se suceden con un sentimiento de intensa añoranza en la obra de este poeta emigrante. Sin embargo, Pedro Herreros nunca volverá a su tierra natal. Fue el quinto hijo del matrimonio formado por Nicolás Herreros y Saturnina Solana, y tuvo seis hermanos, tres varones y

\footnotetext{
${ }^{2}$ Se refiere a su hermana mayor, Catalina. Este libro, Poesía pura, participó en el Premio Municipal de Poesía ciudad de Buenos Aires, y en él incluye el poema "Mi padre", que ya había sido publicado, como acabamos de señalar, en Poemas egotistas (1923). El libro posterior, Cantos de amor (1930) repite el poema "Nocturno castellano" y el poema "A mi hermana Felisa", que igualmente ya se había dado a conocer en Poemas egotistas.
} 
tres mujeres. ${ }^{3}$ Según Felipe Abad León, en su pueblo se desempeñó como dependiente en el "comercio de los Bayo", como así llamaban a la familia de Alfredo Ruiz de la Torre ${ }^{4}$, quien regentó un negocio de venta de "tejidos al pormenor", primero ubicado en la Calle de la Yasa, número 21; y luego en La Plaza, número 7.5

A principios de siglo XX, Arnedo contaba con poco más de 4.000 habitantes. ${ }^{6}$ La cifra demuestra un estadio demográfico y urbano poco evolucionado. La ocupación básica de sus gentes era la agricultura, con un porcentaje, en 1900, del 70\% de la población activa. En este periodo histórico, Arnedo no había alcanzado el progreso económico que conseguirá a partir de la década 1920-1930 con el desarrollo de la industria del calzado. Se vivía fundamentalmente de la agricultura y eran inexistentes todavía las industrias propiamente dichas, contando con un número no muy elevado de artesanos que trabajaban en pequeños talleres cobijando reducidos grupos de obreros. Con una estructura social no muy diferenciada, aunque se hacía evidente el control económico por parte de una clase media de propietarios y profesionales liberales, en los periodos de dificultades económicas, muchos arnedanos emigraron, como ocurrió en las primeras décadas del siglo XX, cuando Arnedo perdió más del 20\% de su población 272 (RODRÍGUEZ, 1999: 13).

En este contexto histórico local, que realmente hacía parte de la España de la época, con un limitado desarrollo del capitalismo industrial y una riqueza nacional que todavía continuaba asociada a la producción agrícola y ganadera, en el terreno personal, Pedro Herreros pierde a su madre Saturnina Solana en diciembre de 1905, a causa de una "neumonía infecciosa", cuando ella contaba con 51 años de edad. Solo dos años más tarde, en septiembre de 1907, muere también su padre Nicolás, a consecuencia de

\footnotetext{
${ }^{3}$ Todos ellos son bautizados en la Iglesia Parroquial de los Santos Mártires (Cosme y Damián) de la ciudad de Arnedo, Provincia de Logroño, Obispado de Calahorra. Felisa Herreros trae el nombre equivocado de Felipa en su acta civil de nacimiento (JMA, RC, T. 21, 43), siendo el correcto el de Felisa, como registra el Libro de Bautizados de la Parroquia San Cosme y San Damián, T. 11 (1893-1899), fol. 85.

${ }^{4}$ Entrevista de Alfonso Rubio a Felipe Abad León, Logroño, 10 de noviembre de 2012. Cfr. también (LEÓN, 1971: 75).

${ }^{5}$ La Matrícula Industrial de 1903 lo registra en La Yasa, 21; y la Matrícula de 1907, en La Plaza, 7. Ya en 1915, en lugar de Alfredo Ruiz de la Torre, aparece como titular Roberto Ruiz de la Torre (AMA, 418/05).

${ }^{6}$ El Censo de población elaborado en el año de 1897 registra un total de la población de derecho de 4.265 habitantes, y una población de hecho de 4259. Tres años más tarde, al 31 de diciembre de 1900, las cifras siguen estancadas, con un total de 4.180 habitantes residentes presentes, 46 habitantes residentes ausentes y 58 habitantes inscritos como transeúntes (AMA, Resumen numérico del censo de población: 1897 [534/10] y $1900[512 / 12])$.
} 
un "colapso cardiaco" y a la edad de 55 años (JMA, RC, T. 30, fol. 119 y T. 31, fol. $123)^{7}$

Herreros queda huérfano de padre y madre poco antes de emigrar a la Argentina en 1908. Su poema titulado "Pero ninguno lloró", del libro Poemas egotistas, nos habla de ese momento (HERREROS, 1923: 8):

\author{
Ya no tenía yo madre \\ ni padre. \\ Y era muy joven cuando me hablaron de emigrar. \\ A mi me encantó. \\ Vería ciudades y tierras y mar...
}

Además de manifestar su orfandad, el poema trasluce, en el hecho de la emigración, motivaciones relacionadas con la necesidad psicológica del cambio ("A mi me encantó./ Vería ciudades y tierras y mar...”). Pero más adelante, en el mismo libro, el poema "La tragedia de ver", añade otras motivaciones, al parecer, económicas (HERREROS, 1923: 12):

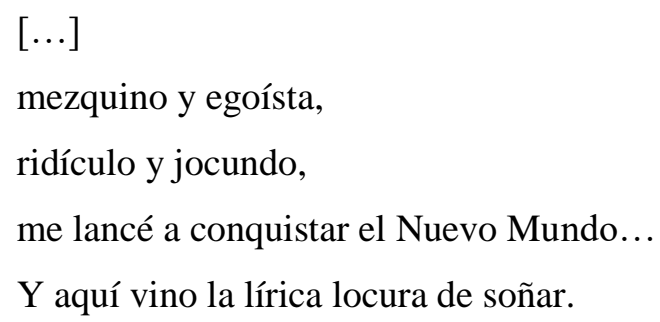

Como sucedió con Pedro Herreros, que ejercía el oficio de dependiente en un establecimiento de venta de textiles, la ausencia de fuertes lazos familiares (la orfandad), la necesidad de aventura ("Vería ciudades y tierras y mar...") y el deseo de mejorar económicamente ("me lancé a conquistar el Nuevo Mundo..."), revelan que individuos provenientes del medio rural, en condiciones de vida que hacían difícil la promoción social y económica interna, no se encuentran cómodos en su cotidianidad. Insatisfechos consigo mismo y con sus circunstancias, deben sobreponerse al cerrado ambiente que los rodea, deben renovar su horizonte vital y mejorar su situación en el

\footnotetext{
${ }^{7}$ Saturnina Solana muere a las diez de la noche de un 7 de diciembre de 1905. Nicolás Herreros, "a las cuatro horas" de un 30 de septiembre de 1907.
} 
aspecto material. Poéticamente, así lo expresa Leopoldo D’ozouville: "Marchan, unos impulsados por su espíritu aventurero e inquieto, otros henchidos por el espejismo de las lejanías, por la sugestión de lo desconocido, por la ilusión de un azar vago y misterioso" (SÁNCHEZ, 2002: 63).

A los motivos ciertos que el propio poeta referencia, se añade otro de no menor transcendencia. El expediente de reclutamiento correspondiente al reemplazo del ejército del año de 1911, declara "prófugo" al mozo Pedro Herreros Solana (AMA, 583/13: Expediente de reclutamiento de 1911). ${ }^{8}$ El 12 de febrero de 1911, reunido en sesión pública a las siete de la mañana el Ayuntamiento de Arnedo, bajo la presidencia del Alcalde Felipe Ucha, se celebra el sorteo de dicho reemplazo que comprendía a 32 mozos sorteables. Haciendo girar dos globos, donde en uno se incluían las papeletas con los nombres de los mozos y el número con que cada cual figuraba en el alistamiento; y en el otro, otras 32 papeletas con un número consecutivo cada una de ellas, dos niños menores de diez años fueron sacándolas de una en una, tocando en suerte a Pedro Herreros, que figuraba con el número 9 en el registro del alistamiento, el número 1.

Después de tallar y reconocer a los futuros soldados, a medida que se les llama por orden del sorteo, se les invita a exponer los motivos que les asisten para eximirse del servicio. El nombre de Pedro Herreros aparece en primer lugar en el expediente y de él se ofrece la siguiente información:

Del sorteo y perteneciente al reemplazo de 1911, soltero, de 20 años de edad, natural de Arnedo, partido de Arnedo, provincia de Logroño, hijo de Nicolás y Saturnina y de oficio del comercio. Sí sabe leer y escribir.

Se dio cuenta de una comunicación del hermano de dicho mozo D. Félix Herreros en la que participa a la Corporación que hace dos años marchó a la República de Argentina. El Ayuntamiento, en vista de la citada comunicación y de conformidad con el parecer del Sr. Regidor Síndico y en presencia del art. 97 de la Ley, acuerda instruir el oportuno expediente de prófugo. Publicado este fallo, no hubo protesta ni reclamación alguna.

\footnotetext{
${ }^{8}$ Esta y la siguiente información referida al sorteo de quintas, está tomada de este expediente.
} 
El 21 de marzo del mismo año, el acta de la clasificación de los soldados, ratificándose en los resultados anteriores, y según lo dispuesto en el caso $4^{\circ}$ del artículo 97 y el artículo 111 de la Ley de Reclutamiento vigente, declara "Prófugo" a Herreros. 9

La Ley de Reclutamiento de 1896 , que modificaba la de 1885 , y por la cual se estaban rigiendo en el sorteo, establecía que eran reclutados anualmente todos los jóvenes que en el año del alistamiento cumplieran 19 años, edad que en 1906 se retrasará hasta los 21. Efectivamente, como sabemos, Herreros cumplía los 21 años en mayo de 1911.

El Ayuntamiento de Arnedo comienza a confeccionar el expediente de reclutamiento en diciembre del año de 1910. Siguiendo la Ley, los alcaldes debían publicar el 1 de enero de cada año un bando haciendo saber que se va a proceder a la formación del alistamiento. El último domingo del mismo mes de enero, en este caso de 1911, se ratificaba el alistamiento y se recogían las reclamaciones o comunicaciones pertinentes por parte de los interesados, padres, tutores o parientes en grado conocido. Estas fechas y la comunicación, si es cierta, que presenta Félix Herreros, el hermano mayor de Pedro, diciendo que este último marchó "hace dos años" a Argentina, confirman que emigró entre fines de 1908 y principios de 1909. De la misma manera, los datos evidencian que en ese momento de la partida se dedicaba al "oficio del comercio".

La duración de las prestaciones militares estaba establecida en doce años para los soldados destinados al ejército peninsular y cuatro años para los enviados a ultramar. Durante los doce años, los jóvenes pasaban por diferentes situaciones: 1. Mozos en las cajas de recluta, 2. Soldados en servicio activo permanente (con una duración de tres años en tiempos de paz y generalmente de cuatro en tiempos de guerra), 3. Soldados en reserva activa o con licencia, 4. Reclutas en depósito o condicionales y 5. En la segunda reserva. Eran activas las situaciones segunda, tercera y cuarta, y en ellas había que servir durante seis años, extinguiendo el resto del total obligatorio en la primera y quinta situación. La legislación castigaba con duras penas a los prófugos y desertores y fijaba

\footnotetext{
${ }^{9}$ El artículo 97 en cuestión, según los casos, declara a los mozos: 1. Excluidos total o temporalmente del referido servicio, 2. Soldados, 3. Soldados condicionales; y 4. Prófugos. La cuarta categoría comprende a los individuos que "dejen de concurrir a los llamamientos que se les dirijan antes de ingresar personalmente en las Cajas de recluta o de recibir los pases y ser enterados de la legislación penal militar". El artículo 111 dice así: "La determinación del Ayuntamiento comprenderá la declaración de ser o no prófugo el individuo de quien se trata, y en el primer caso la condenación al pago de los gastos que ocasiones su captura y conducción” (LEY DE RECLUTAMIENTO, 1896: 37 y 41).
} 
en 1500 pesetas el precio de la redención para la península y en 2.000 pesetas para los conflictos militares de ultramar como fueron los de Cuba (1895-98), Filipinas (1896-98) y Puerto Rico (1898). Tales cifras, que se mantuvieron hasta 1912, eran prohibitivas para la casi totalidad de la población, solo estaban al alcance de reducidos grupos sociales como las élites gobernantes y clases medias urbanas (LEY DE RECLUTAMIENTO, 1896: 3 y 8; ANDRÉS, 2002: 185; GARCÍA y RUIZ, 2002: 66$67)$.

El sistema de reclutamiento era, por tanto, clasista. Esta situación, a la que se sumaba la prolongada duración del servicio activo y las malas condiciones de vida en los cuarteles, aumentaron las contestaciones sociales a la prestación militar. Eludir el servicio militar fue una causa de la emigración que se dio con frecuencia a fines del siglo XIX y comienzos del XX, cuando el país, además, estuvo comprometido con esfuerzos bélicos en lugares como Cuba, Filipinas, Puerto Rico, Melilla y Marruecos. Ante la eventualidad de ser destinado al frente de batalla, los jóvenes, antes de cumplir la edad militar, emigraban.

El Consejo Superior de Emigración dio en 1916 unas cifras que mostraban claramente el espectacular incremento del número de prófugos en España: 9`74\% de los mozos en $1907 ; 11^{\prime} 16 \%$ en 1910 y $22^{\prime} 09 \%$ en $1914 .{ }^{10}$ Sin poder diferenciar si los mozos que salen del país son prófugos porque son emigrantes o son emigrantes porque son prófugos, el hecho de no incorporarse a filas estaba severamente castigado. Tanto la legislación civil como la militar consideraban al prófugo como a un delincuente y fueron endureciendo las medidas contra ellos. ${ }^{11}$ Sin embargo, la emigración hacia América de estos mozos no encuentra demasiadas dificultades. Además de que se reconocía la existencia de agencias de emigración clandestina y la tolerancia de empresas y sociedades que contrataban a quienes ya habían sido declarados prófugos, la

\footnotetext{
${ }^{10}$ Aun siendo La Rioja una de las provincias con menor número de prófugos en la nación, el aumento de los mismos es progresivo entre fines de siglo XIX y la primera década del XX. En 1897 suponen alrededor del 1\% del total de alistados en la provincia y alcanzan algo menos del 5\% en 1913 (LARA, 2000: 179).

${ }^{11}$ Los prófugos eran condenados por procedimiento administrativo (la declaración del Ayuntamiento confirmada luego por la Diputación) y se les imponía penas militares (servicio en Ultramar con recargo de dos años), administrativas (multas previstas por la Ley) y penales (indemnizaciones), a pesar de que todavía no pertenecían a la jurisdicción militar, ya que ni siquiera habían sido declarados soldados. En la última década del siglo se endurecieron las penas al tiempo que los delitos contra la Ley de Reclutamiento aumentaron en progresión geométrica, siendo evidente la incapacidad del Estado para atajar el problema (GÓMEZ, 1996: 259-260).
} 
sociedad adoptó una actitud tolerante respecto a la emigración que eludía el servicio militar. Los mozos, incluso aquellos que estaban próximos a su incorporación a filas, diligenciaban sin excesivos obstáculos los correspondientes trámites de los servicios de emigración en los puertos de embarque. Las salidas, además, se vieron favorecidas desde finales del siglo XIX con un precio del pasaje muy inferior de lo que costaba la redención del servicio militar en metálico, pues el pasaje por atravesar el Atlántico alcanzaba la cantidad de poco más de 200 pesetas.

Por otro lado, excepcionales fueron las sanciones contra las familias de quienes eran declarados prófugos. De forma casi ritual, los expedientes de prófugos formados por las corporaciones locales, cuando los había, argumentaban que el prófugo ha actuado por "razones de necesidad" y que sus progenitores no han colaborado con él en "eludir sus obligaciones militares" (GARCÍA Y RUIZ, 2002: 67-68). ${ }^{12}$ Aunque, en algunos casos, como es el del mozo arnedano Venancio López Saravia, en el expediente de prófugo que se le formó entre los meses de marzo y abril del año de 1899, se manifiesta explícitamente que no son las causas económicas, sino el llamamiento a quintas lo que origina su huida que, en esta ocasión, contó con la complicidad de su padre, quien antes de partir para ultramar, según dice el mismo expediente, envía a su hijo a Bilbao:

En el mes de noviembre del año último, el mozo Venancio López Saravia, ${ }^{\circ}$ 8 del sorteo, se hallaba bien empleado en la casa comercio de los Señores Alfredo y Roberto Ruiz, de esta ciudad; y sin saber por qué, o sin duda porque veía que estaba próximo el alistamiento para el servicio militar, se marchó de la casa de dichos Señores, y en unión de su padre Cipriano, con

\footnotetext{
${ }^{12}$ Desde mediados del siglo XIX, las políticas populacionistas de algunas repúblicas sudamericanas promovieron la implantación de agencias colonizadoras en La Rioja, donde se denunció la existencia de redes de ganchos y falsos reclutadores que trabajaban al servicio de consignatarios en puertos de salida cercanos como los de Barcelona, Bilbao, Santander, Coruña y Vigo. Quienes no conseguían cruzar los controles portuarios, encontraban una solución desviándose a puertos extranjeros. Burdeos fue la salida frecuente de la emigración clandestina en La Rioja. A partir de la Ley de emigración de 1907, que estableció restricciones de salida a los varones sujetos al servicio militar, la emigración clandestina se nutrió preferentemente de jóvenes en edad militar que recurrieron a estas redes para eludir la posibilidad de ser enviado a la guerra de Marruecos (86-88). Ni los cazadores de prófugos, que los había, ni los severos castigos sirvieron para acabar con el profuguismo: "Los prófugos siempre contaron con ayudas extras, agentes encargados de proporcionar documentación falsa o de trasladarlos a lugares seguros, familiares convertidos en ocultadores y ayuntamientos excesivamente permisivos. Amigos, vecinos y familiares prestaron toda la ayuda posible al prófugo, a sabiendas del riesgo que corrían como cómplices" (GÓMEZ, 1996: 407).
} 
fecha del citado mes de noviembre marchó de esta ciudad sin ser ya visto por ninguna persona de dicho pueblo, sin duda alguna para Buenos Aires, donde hoy se halla; es decir que su referido padre Cipriano fue cómplice en la fuga de su citado hijo, por lo que a uno y a otro debe exigírseles la responsabilidad que la Ley previene, pues es un hecho claro y evidente que el mozo Venancio [...] se ha fugado con el solo fin de evadirse de la responsabilidad de quintas (AMA, 538/9: Expediente de prófugo del mozo Venancio López Saravia, 1899).

Junto a las fuertes crisis económicas, las guerras civiles y coloniales en las décadas finales del siglo XIX, contribuyeron a reforzar en las capas populares el sentimiento continuo de hostilidad a las quintas. Son los años precisamente en que los “hermanos más viejos" de Pedro Herreros, Félix (nacido en 1876) y Paulino (nacido en 1878), viven la experiencia del llamado a quintas, en los años de 1895 y 1897 respectivamente, cuando por entonces se estaban dando los conflictos militares de Filipinas (1896-98), Puerto Rico (1898) y, sobre todo, el de Cuba (1895-98). ${ }^{13}$ Carlos Gil relata además la agitación social que en las ciudades de Logroño y Haro suscitó en 1895 el llamamiento que el Gobierno hizo el 29 de julio a concentrar a los soldados de la reserva activa del reemplazo de 1891 para trasladarlos a Cuba (ANDRÉS, 1995: 7879). La guerra de Cuba originó toda una serie de imágenes negativas que se perpetuaron durante años después. Los "consejos" para emigrar, nunca desvelados por Herreros, a los que se refiere su poema ya citado, Pero ninguno lloró: "Mis hermanos más viejos/ me dieron al marchar/ muchos consejos", con toda seguridad, hay que relacionarlos con el hecho del llamado a filas que tres años después de partir para la Argentina, en 1911, se le haría a nuestro poeta. El examen de la edad de los emigrantes riojanos varones que hacen Gurría García y Lázaro Ruiz, revela, además, un elemento definidor de la emigración ultramarina: "El hecho de que los jóvenes marchen sin haber cumplido, según las épocas, 20 ó 21 años indica bien a las claras que el viaje se emprende mayoritariamente antes de la prestación del servicio militar" (GARCÍA y RUIZ, 2002: 66).

\footnotetext{
${ }^{13} \mathrm{Su}$ hermano Francisco, solo tres años mayor que Pedro, a quien le tocaba alistarse en el año de 1906, murió, como dijimos, tres años después, en 1909, a causa de una tuberculosis pulmonar y al poco tiempo de que Pedro Herreros llegara a Buenos Aires.
} 
El profuguismo se relacionó fundamentalmente con la imposibilidad de renunciar al sueldo del trabajo cotidiano que por incorporarse a filas los reclutas debían abandonar y, junto a la emigración, fue la postura obligada que tomaron los sectores populares más desfavorecidos: "Colocados en la alternativa de tener que escoger entre una legalidad que les enviaba a morir en los trópicos por una causa con la que apenas se sentían identificados, y una ilegalidad que les permitía al menos la esperanza de mejorar sus condiciones de vida, numerosos españoles elegían la segunda posibilidad" (GÓMEZ, 1996: 410). Es la posibilidad, manifiesta en el mismo Expediente de reclutamiento de 1911, que, al lado de Pedro Herreros, eligen los arnedanos que aparecen ubicados en Cuba (Nemesio Jubero Pastor) y en Buenos Aires: Tomás León Calvo, Sinforiano Garrido Tomás; y quien fuera el fotógrafo artístico Zoilo Puerta Roldán, que acabaría viviendo en Chile, donde entabló amistad con la poetisa Gabriela Mistral, llegando a formar parte del mismo grupo teosófico que los congregaba. ${ }^{14}$

Como Venancio López Saravia, el joven empleado en la casa comercio arnedana de Alfredo y Roberto Ruiz de la Torre que en 1899 se convirtió en prófugo huyendo a Buenos Aires, nueve años después, Pedro Herreros, igualando los destinos, abandonó el mismo establecimiento textil de los Ruiz de la Torre donde trabajaba como dependiente, para vivir en la misma ciudad, la capital de la nación Argentina que, durante aquellos años, a pasos agigantados, se estaba transformando.

\section{Pedro Herreros atrapado por la modernidad}

A comienzos del siglo XX, Argentina mantenía un crecimiento económico que seguía alentando a la emigración europea, pero a finales de la primera década se detecta ya un cambio en la coyuntura económica. Pedro Herreros llega a Buenos Aires en 1908 y al poco tiempo, en mayo de 1909, presencia una convocatoria de huelga general que acuarteló a las tropas gubernamentales. En 1910 comienzan a celebrarse en toda la Argentina los fastos del Centenario de la Emancipación que exhiben ante el mundo la imagen de un país que pretendía ser rico internacionalmente y una potencia en la América Latina. Sin embargo, a lo largo de 1910 se experimentó una paralización

\footnotetext{
${ }^{14}$ Cfr. (GOYA y CORTÉS, 2011). Pedro Moral Quemada, natural de Belorado (Burgos, España) fue en Chile íntimo amigo de Zoilo Puerta y en su libro de memorias titulado Moral quemada describe el trayecto de su viaje migratorio a Buenos Aires, donde en principio llegó: Belorado-Briviesca-HendayaBurdeos-Vigo-Islas Canarias-Río de Janeiro-Montevideo-Buenos Aires (QUEMADA, 1946: 31-56).
} 
progresiva de la actividad comercial y comenzaron a proliferar noticias alarmantes sobre el paro o el subempleo en Buenos Aires.

Desde finales de 1912, la crisis se generalizó en todos los sectores económicos. El Diario La Rioja, en ese mismo año, hablaba de "un desempleo masivo de españoles que vagan por las calles escuálidos y hambrientos, sin otro deseo que retornar". El deterioro de la situación social se agudiza y en 1914, en el mismo Diario leemos: "La situación es peligrosa para ese enorme número de trabajadores que después de haber confiado en la virtud prolificadora de la tierra argentina se ven obligados a reconocer el engaño en que han vivido ante las obras de los hombres, tan opuestos a la bella promesa de la tierra" (GARCÍA y RUIZ, 2002: 66-67, 70-71 y 107).

Este desengaño personal del emigrante es expresado por Pedro Herreros en el poema, de sabor amargo, titulado "La tragedia de ver", del libro Poemas egotistas (1923): “[...] me lancé a conquistar el Nuevo Mundo...// Y aquí vino la lírica locura de soñar/ Y fue bien triste el despertar..." (HERREROS, 1923: 12). Sin dejar de incluir el humor sano característico del poeta, el poemario mantiene mayoritariamente un tono trágico y desesperanzado al hablar de su situación personal como emigrante y de un país que no ofrece protección al desvalido (HERREROS, 1923: 51, “Como un perro”): “[ ...] Además, ¡¿qué interesa mi vida silenciosa/ a este Buenos Aires de negocio y de estruendo?!// En esta gran ciudad/ yo sé que estoy expuesto/ a morir cualquier día/ como un perro".

Pero antes de estos, directos, sinceros y egotistas poemas, Pedro Herreros, en Buenos Aires grotesco y otros poemas (1922), ya había hablado de los dramáticos efectos de la crisis económica que estaban sufriendo los emigrantes en Buenos Aires. Así dice su poema titulado “Un indiano” (HERREROS, 1922: 71, “Un indiano ...”):

Dejó su hogar en Castilla

e hizo rumbo a Buenos Aires.

Desembarcó. Y varios años

fue un honrado comerciante.

Ahora anda por el suburbio

-hecho un grasiento "atorrante" -

con su honro y con sus piojos...

¡sin valor para matarse! 
Cuando publica Buenos Aires grotesco, Pedro Herreros cuenta ya con 32 años, todavía no ha encontrado ese "amor" que "venga solo y suave", ni condiciones laborables estables: "De todos los que estamos en el bar (escribe)/ ninguno tenemos hogar". El "cafetín" sigue siendo su "casa" y cuando "despierta la ciudad" anda "vagando por las típicas calles suburbanas" de Buenos Aires (HERREROS, 1922: 26, "Marineros"; 69, “A Lucette”; 70, “Temor”; 83, "La busca”).

Los poemarios de Buenos Aires grotesco y otros motivos (1922), Poemas egotistas (1923) y Las trompas de Falopio (1924) describen la cotidiana realidad del poeta, muy transformada ya respecto a los ingenuos ambientes que mostraba en 1915 El Libro de los Desenfados. Son textos que resultan ser un diario de cafés, tabernas, calles y prostíbulos.

Como Baldomero Fernández Moreno, Pedro Herreros también salió de España para radicarse definitivamente en la Argentina. Pero si el primero representa al inmigrante acompañado de familia, que se ama a sí mismo y ama la tierra donde ha venido a vivir y en la que también había nacido de padres castellanos, Pedro Herreros es un emigrante español que llega a Buenos Aires despojado de todo, sin recursos económicos durante mucho tiempo, huérfano de toda familia cercana; un autoexiliado forzado que interiormente debe confrontar y conciliar su situación personal con las injusticias sociales que se encuentra en la Argentina del momento.

El recuerdo de un lugar que ahora resulta extraño en Buenos Aires, como es el lugar pequeño y hermético de la población de Arnedo donde hasta el momento de su emigración había transcurrido su infancia y su adolescencia, se repite en todos sus libros dados a conocer en la capital argentina. El recuerdo de su terruño natal es constante y no puede desprenderse de él; más que amar la Argentina, como Fernández Moreno lo hace desde su instalación cómoda y consciente en ella, Pedro Herreros la ve y la juzga sin miramientos. Si en el poeta argentino el juicio va dejándose caer a medida que el poema combina escenarios y personajes con estados sentimentales, en poemas de Ciudad (1917), como ejemplo, que manifiestan la experiencia del cambio en la sociedad bonaerense y articulan reacciones y afectos: nostalgia, transformación, recuerdo, lamento, actitudes que el poeta adopta frente a un pasado cuya desaparición es vivida como irremediable ("Setenta balcones y ninguna flor", "Ciudad", "Recova", "Ciudad", “Árboles de la Avenida”); ${ }^{15}$ en Herreros, y esto es muy frecuente en toda su obra, su

\footnotetext{
${ }^{15}$ Sobre la configuración ideológico-cultural que emerge de una particular "estructura de sentimiento" y articula reacciones y experiencias de cambio, cfr. (SARLO, 1988: 31-43).
} 
estilo personal, directo, casi violento, a menudo envuelto en marcas autobiográficas, se enfrenta a las situaciones impuestas por los nuevos tiempos: "Detesto (dice) la indumentaria/ que hay que usar en este tiempo" ("Pequeña oda panteísta"); en "este siglo...muy científico, muy fecundo...en bárbaras violaciones, y en salvajes atropellos...y en egoísmos ciegos, yo soy un nuevo Quijote" ("Esperanza”).

Explícitamente plantea un conflicto con el orden presente, se lamenta de que las relaciones entre los hombres se reduzcan utilitariamente al orden dinerario ("El dinero"), y escribe contra la concepción burguesa que va poblando "este Buenos Aires de negocio y de estruendo": "Burguesa que vas pasando/ cargada de oro y de sebo...Esas cadenas que llevas,/ magníficas de oro grueso,/ quizás algún día sirvan/ para colgaros del cuello" ("Burgueses"). Son versos estos últimos de Poemas egotistas (1923) que se recrudecen en Córdoba bajo mi ojo (1936), un texto de compromiso que reivindica justicia social en tono muchas veces panfletario: “Abajo la burguesía./ Abajo los asesinos./ Muera el oro y la tiniebla..." (“Manifestación”).

Fernández Moreno sale a la calle en busca de esa tensión que la modernidad produce en sus gentes, sale para captar y re-crear haciendo de ello un modo de vida para el cual decidió abandonar su oficio de la medicina. El vagabundeo de Pedro Herreros, en cambio, no es querido y se ve obligado a padecerlo. El poema titulado "La busca" es muy significativo:

Despierta la ciudad. Y en un momento hormiguea la vida en sus entrañas.

$[\ldots]$

Yo, a esta hora febril, ando vagando

por las típicas calles suburbanas.

Cada puerta que viene es un misterio

que una emoción, en su interior, me guarda.

Muchas veces, las más, es la emoción

de creer encontrar...y no hallar nada.

(“La busca”, Buenos Aires grotesco y otros motivos, 1922)

El rechazo a la burguesía que Fernández Moreno muestra en su poema titulado "Burgueses", no es el mismo desprecio radical que siente Herreros ("anticlerical violento" lo llama Nalé Roxlo en sus memorias) por ellos (“Abajo la burguesía./ Abajo 
los asesinos"), pues su presunta negación a ellos, la de Fernández Moreno, "no es más que la velada afirmación de un orden". El poeta argentino se interna en la multitud, pero no es un marginal y está integrado en el acontecer cotidiano de su ciudad (MONTELEONE, 2006: 268-269).

Monteleone habla en Fernández Moreno de la figura del "bohemio" como representante del poeta caminante y de su imagen social, y atribuye los rasgos de esa figura al abandono de la profesión de médico por la de poeta. Pero en realidad, Fernández Moreno, nunca formó parte de la "bohemia", entendida ésta, según Marx, como "toda la masa indeterminada, desmembrada, traída y llevada de aquí para allá", a la que los franceses en el siglo XIX llamaban "bohème" (BENJAMIN, 1990: 24) ${ }^{16}$. Abandona la medicina para dedicarse exclusivamente a las letras, pero con algunas cátedras secundarias de literatura e historia. La medicina y la enseñanza fueron, pues, sus labores extraliterarias y también sus medios de vida.

Si Fernández Moreno en el callejeo era consciente de la fragilidad de una existencia que le movía al acto re-creador (“El mundo, en torbellino, pasa rodando./ Tú mismo no eres más que otra cosa que rueda": "La calle”), el despertar de Pedro Herreros en una ciudad de emigrados como él, en la que todavía a comienzos de la segunda década del XX soporta (cito de él) una "vida sin amor ni hogar", "de miseria y soledad", le hace ser consciente de una existencia marginal que no se integra en el sistema de la gran ciudad. Pedro Herreros sí es un "bohemio" que en buena medida adopta los gustos neorrealistas de la escuela de Boedo; y un "excéntrico" que habla de sus " medias y botas rotas"), un hombre común desgastado, como decía Walter Benjamin. Herreros busca asilo entre la multitud y Buenos Aires le hace guiños de fantasmagoría ("sigo como un fantasma bajo los focos eléctricos"), un fantasma real en un lugar real que tan pronto es paisaje como estancia edificando el bazar que hace que el callejeo sea útil para la venta de mercancías.

En un mundo que posibilita multitud de nuevas experiencias para un emigrante que representa el "movimiento arquetípico" del campo a la ciudad de millones de jóvenes a fines del siglo XIX y principios del XX, Herreros mantuvo durante muchos años fuertes lazos con el pueblo campesino donde nació a través de sus cartas, donde con toda seguridad describiría la experiencia de su vida en la ciudad multiforme de

\footnotetext{
${ }^{16}$ La individualidad de Fernández Moreno hizo que se mantuviese al margen de bohemias: "Mientras se aplica al estudio de la medicina, recluido en la sala de un hospital, hay en Buenos Aires muchachos de su misma edad que se entregan a una bohemia entre literaria y revolucionaria” (MORENO, 1956: 125).
} 
Buenos Aires, y las cartas de su hermana Felisa ("cartas cordiales", las llama el poeta, donde todo en ellas "son dulces bálsamos fraternales para mi corazón y para mi tormento", cartas que recibe como una "epifanía"). Herreros experimenta la vida metropolitana como un choque perpetuo de prejuicios y contradicciones. Anhela algo sólido a lo que asirse como es la estabilidad laboral y "el amor de una mujer amada", pues se sigue sintiendo "el ser más triste y desdichado" y camina como un fantasma entre la multitud.

El poeta vive dentro de una atmósfera de agitación y turbulencia que la ciudad ha creado con fábricas, tranvías, diarios, con acumulación multinacional de capital y movimientos sociales de masas, con formas de vida, en definitiva, capitalistas, donde se privilegia la propiedad privada, el trabajo asalariado, el valor de cambio y la persecución insaciable de ganancias. Es una atmósfera de "vértigo y embriaguez psíquicos" donde se destruyen las barreras morales y los vínculos personales, donde se expande el desarreglo de la personalidad y aparecen fantasmas en las calles y en el alma; es la atmósfera donde nace la "sensibilidad moderna". Donde, según Baudelaire ("El pintor de la vida moderna") el artista debe, como un héroe, levantar su hogar, entre la multitud, "en medio del flujo y el reflujo del movimiento", entre "lo fugitivo y lo infinito" (BERMAN, 1991: 4-5 y 141-144). Y a su manera, esto es lo que hizo Herreros, describir, desde la posición de inestabilidad que le había creado la propia "modernidad", los procesos que experimentaba Buenos Aires, sintiéndose un ser vivo más dentro de un sistema económico que destruye las posibilidades humanas que crea, poniendo su propia alma y sensibilidad en estas transformaciones, atacándolas y dándoles vida en su obra, irónico hasta en sus momentos de mayor compromiso social.

La ciudad "grotesca" del poeta es la ciudad que exhibe al asocial, donde incluye a un determinado sustrato social, al melancólico bohemio, al itinerante marinero, al vendedor de las esquinas y a quien no puede faltar en el mercado capitalista de la gran ciudad moderna: la prostituta, un personaje más visible quizá que los anteriores en el contexto social del momento, que expone la mercancía por antonomasia, la prostituta de Buenos Aires grotesco y otros motivos y la prostituta protagonista de Las trompas de Falopio que es a la vez vendedora y mercancía.

En la ciudad moderna, el bazar es el último golpe del "flâneur", quien se dirige a él supuestamente para "echar un vistazo", pero en realidad encuentra a un comprador. Comenzando ya a familiarizarse con el mercado, el "flâneur" aparece como bohemia: “A lo indeciso de su posición económica corresponde la indecisión de su función 
política. Esta se hace palpable en los conspiradores profesionales que pertenecen por entero a la bohemia" (BENJAMIN, 1990: 184).

Sin ser clasificado entre los poetas anarquistas, comunistas o socialistas; sin una adscripción política definida, como indica la antología de Álvaro Yunque (Poetas sociales de la Argentina, 1810-1943), Herreros sí sintió el “desequilibrio social” y de él escribió con aspereza. Como la poesía del grupo de Boedo y la de otros escritores de clara afiliación política, la "poesía social” de Herreros toma su fuerza del pathos rebelde del proletariado y se sitúa del lado del asocial:

\author{
No soy -ni quiero- ser más \\ que un obrero. Ni orgulloso, \\ ni modesto. Un obrero que os da \\ el corazón y el cerebro, prosa \\ a prosa y verso a verso. \\ ("Soy un obrero", en Poemas egotistas)
}

Poemas egotistas (1923) muestra a un Herreros que se piensa desestabilizado socialmente. Se hace desesperante la "amarga tragedia" de su vida, no encuentra "consuelo" a su "desgracia" y siente la necesidad del suicidio:

¡Sólo la muerte tiene

lo que a mí me hace falta!

Sin nadie la dársena.

La mirada vaga,

voy con tentaciones

de tirarme al agua.

("Esplín")

El suicidio como reacción a un modo de vida de impulsos capitalistas, de aglomeraciones humanas, de aceleración y angustia; un modo de vida egoísta donde las relaciones mediatizadas son propias de una sociedad moderna, sea en el mercado de trabajo, en las formas de producción, en el ámbito institucional, o en las prácticas públicas y privadas del acontecer cotidiano (“A qué vivir, Señor, en este mundo,/ donde la Humanidad/ es un rudo rebaño de alimañas,/ cerniéndose voraz, los ojos inyectados y afiladas las uñas": “Sed de Dios”). Un mundo que reduce las relaciones a decisiones 
monetarias, a méritos y eficiencia, a una nueva economía que impone pautas anónimas y despersonalizadas; un mundo que no es el mundo rural y añorado de su poema titulado "Paisaje castellano", del que procede Herreros; unas nuevas formas de vida que provocan malestar y suscitan un conflicto con sus valores personales ${ }^{17}$ :

\author{
Cada día es más amarga mi pena \\ nacida en mi alma al choque \\ de mi vida con la vuestra. \\ Los unos me hacen odiar. \\ Y los otros me envenenan. \\ Mi amargura es la de un hombre \\ traspasado de tristeza \\ sin más esperanza que \\ ser feliz bajo la tierra. \\ ("Desesperanza")
}

Las transformación veloz de la capital argentina, su "monstruosidad" creciente abruma y es amenazadora: "Las aglomeraciones de hombres son amenazadoras (dice el novelista Léon Daudet, hijo de Alphonse Daudet). El hombre necesita del trabajo, cierto, pero también tiene otras necesidades...Entre (estas) otras necesidades tiene la del suicidio, que se afinca en él y en la sociedad que le forma; y es más fuerte que su instinto de conservación" (BENJAMIN, 1990: 104). Este es el rostro de Buenos Aires que, a comienzos del siglo XX recibe, como el París de Baudelaire, la "passion moderne" que el poeta francés reconocía en el suicidio.

Pedro Herreros fue atrapado por lo moderno. Su pasado biográfico remarcaba lo que había perdido y en el presente de la ciudad moderna fue a la vez el que mira y es mirado como un flâneur que pasea por los barrios centrales y periféricos, introduciéndose y comprendiéndola, por padecerla, en la pobreza nueva de la gran ciudad y en las formas de una marginalidad que siempre intentó conciliar con una deseable vida reparadora.

\title{
Conclusión
}

${ }^{17}$ Véase (SARLO, 1988: 32). 
Pedro Herreros fue testigo y partícipe directo del ambiente literario de las tres primeras décadas del siglo veinte bonaerense, una época de transformaciones sociales fundamentales para innovar en todos los terrenos artísticos. Es una figura, por tanto, la del poeta español, que inevitablemente nos conduce al estudio del contexto histórico argentino y al estudio de sus relaciones con escritores fundamentales de la literatura argentina de la época.

Si Fernández Moreno en el callejeo era consciente de la fragilidad de una existencia que le movía al acto re-creador, el despertar de Pedro Herreros en una ciudad de emigrados como él, en la que soportó, según sus versos, una "vida sin amor ni hogar", "de miseria y soledad", le hace ser consciente de una existencia marginal que no se integra en el sistema de la gran ciudad. Sin ser clasificado como poeta anarquista, comunista o socialista; sin una adscripción política definida, Herreros sí sintió el desequilibrio social y de él escribió con aspereza a partir de su segundo poemario publicado, Buenos Aires grotesco y otros motivos (1922). A partir de ahí, su obra se envolvió de marcas autobiográficas que describen su realidad vivencial en las calles, cafeterías, librerías y prostíbulos de la capital argentina.

La escritura autobiográfica no se reduce sólo a las biografías, autobiografías, memorias, diarios, correspondencias, cuadernos de viaje. La poesía de Pedro Herreros, todavía hoy una gran desconocida, nos revela así que es posible también extraer de este género literario, rasgos autobiográficos que pueden ponerse en consonancia con la realidad social del momento. También las señales autobiográficas de una obra modesta como la de Herreros, apoyan la reconstrucción histórica de una época y desvelan matices desde lo marginal, desde la difícil, tal vez nunca conseguida, integración del poeta en el mercado capitalista de la gran ciudad moderna.

\section{Fuentes}

\section{Fuentes de archivo}

Archivo del Juzgado Municipal de Arnedo (La Rioja, España) (JMA): Registro Civil (RC).

Archivo Municipal de Arnedo (La Rioja), (AMA).

Archivo de la Parroquia San Cosme y San Damián de Arnedo (La Rioja).

\section{Impresas}

Ley de Reclutamiento y Reemplazo del Ejército de 11 de julio de 1885. Modificada por la de 24 de agosto de 1896. León: Imprenta de la Diputación provincial, 1896. 


\section{Prensa}

Diario Crítica (Buenos Aires) 1927.

\section{Entrevistas}

LEÓN, Felipe Abad (10 de noviembre de 2012). Entrevista realizada por Alfonso Rubio. España (La Rioja).

\section{Obra poética de Pedro Herreros}

HERREROS, Pedro (1915). El libro de los Desenfados. Contiene además este pequeño volumen, versos sobre otros asuntos, que pueden servir de provechoso pasatiempo á quien lo leyere. Buenos Aires: Imprenta de José Tragant. . (1922). Buenos Aires grotesco y otros motivos. Buenos Aires: Editorial Samet. (1924). Las Trompas de Falopio (1915-1923). Buenos Aires: Sagitario. (1926). Poesía pura. Buenos Aires: Talleres gráficos Damiano. . (1923). Poemas egotistas. Buenos Aires: Talleres gráficos Damiano. (1930). Cantos de amor. Buenos Aires: Librería Cervantes de Julio Suárez.

\section{Referencias bibliográficas}

LEÓN, Felipe Abad (1971). 25 arnedanos universales. El río Orenzana y su término. Arnedo: Editorial Ochoa.

BENJAMIN, Walter (1990). Poesía y capitalismo (Iluminaciones II). [El país del Segundo Imperio en Baudelaire: La bohemia]. Madrid: Taurus.

BERMAN, Marshall (1991). Todo lo sólido se desvanece en el aire. La experiencia de la modernidad. Bogotá: Siglo Veintiuno.

GÓMEZ, Albino Feijóo (1996). Quintas y Protesta Social en el Siglo XIX. Madrid: Ministerio de Defensa.

MORENO, César Fernández (1956). Introducción a Fernández Moreno. Buenos Aires: Emecé Editores.

LARA, Beatriz Frieyro de (2000). El reclutamiento militar en la crisis de la Restauración: el caso riojano (1896-1923). Logroño: Instituto de Estudios Riojanos.

SÁNCHEZ, Juan Antonio García (2002). La Rioja y los riojanos en Chile (1818-1970). Logroño: Instituto de Estudios Riojanos / Gobierno de La Rioja.

ANDRÉS, Carlos Gil (2002). "Dos riojanos en la guerra de Cuba. Pequeñas historias del 98 ¿Historia pequeña?”, Berceo, no 142.

(1995). Protesta popular y orden social en La Rioja de fin de siglo, 1890-1905. Logroño: Instituto de Estudios Riojanos, 1995.

GARCÍA, Pedro A. Gurría y RUIZ, Mercedes Lázaro (2002). Tener un tío en América. La emigración riojana a ultramar (1880-1936). Logroño: Instituto de Estudios Riojanos.

RODRÍGUEZ, Pedro López (1999). Arnedo bajo el signo del cambio. Transformación económica y poder local ante los siglos XIX y XX. Logroño: Instituto de Estudios Riojanos / Ayuntamiento de Arnedo.

MONTELEONE, Jorge (2006). "Baldomero Fernández Moreno: el poeta en la ciudad", Literatura argentina del siglo XX, T. 2 Yrigoyen: entre Borges y Arlt, 1916-1930 coord. VIÑAS, David. Buenos Aires: Paradiso.

QUEMADA, Pedro Moral (1946). Moral quemada. Buenos Aires: Sociedad Cooperativa de Escritores. 
RUBIO, Alfonso (2018). La hoja de vida de un poeta español en Buenos Aires. Pedro Herreros, 1890-1937. Logroño: Instituto de Estudios Riojanos.

SANTONJA, Gonzalo (1995). Un poeta español en Cuba: Manuel Altolaguirre. Sueños y realidades del primer impresor del exilio. Barcelona: Galaxia Gutenberg.

SARLO, Beatriz (1988). Una modernidad periférica: Buenos Aires 1920 y 1930. Buenos Aires: Nueva Visión.

GOYA, Mauricio Toro y CORTÉS, Fernando San Martín, Coquimbo: Vida y obra de Zoilo Puerta Roldán. Coquimbo: Centro de Estudio de la Imagen Coquimbo, 2011.

Artigo recebido em 12 de fevereiro de 2019.

Aprovado em 30 de novembro de 2019.

DOI:10.12957/intellectus.2019.47128 